\title{
Cacela-A-VelHa EN EL CONTEXTO DE LAS ACTIVIDADES MARÍTIMAS DEL GHARB-AL-ANDALUS
}

CRISTINA A. TÉtÉ Garcia Bolseira de Doutoramento FCT | Departamento de Historia I de la Universidade de Huelva | CEAUCP

Recibido: 4/03/2015

Revisado: 28/04/2015
Aceptado: $28 / 04 / 2015$

Publicado: 30/05/2015

\section{RESUMO}

Cacela-a-Velha é uma pequena povoação do Algarve oriental, situada sobre arriba miocénicas, bordejada por uma laguna protegida do oceano por um cordão arenoso. Apresenta-se resumo do estudo baseado numa metodologia que correlaciona diferentes elementos de análise histórica e estudos arqueológicos. Os objectivos desta investigação foram alcançar o conhecimento histórico do povoamento no período de transição entre o final da época almoáda, a fase de guerra, a conquista e o establecimento dos novos senhores daquela terra.

\section{ABstRact}

Cacela-a-Velha is a small village in Eastern Algarve, placed on Miocene cliff, bordered by a protected lagoon from the ocean by a sandy spits. Study summary based on a methodology that correlates different elements of historical analysis and archaeological research is presented.

The purpose of this study were to reach the historical knowledge of the settlement in the transitional period between the end of the Almohad epoch, the phase of war, the conquest and the advent of the new lords of that piece of land.

\section{Palavras Chave}

Arqueologia Medieval; Metodologia Histórica; Almóadas; Conquista; Algarve.

\section{KEYWORDS}

Medieval Archaeology; Historical Methodology; Almohad; Algarve (Portugal).

cgarcia22@live.com.pt 


\section{INTRODUÇÃO}

Cacela-a-Velha é uma pequena povoação do Algarve oriental, situada sobra arriba miocénica, bordejada por laguna protegida do oceano por cordão arenoso, designado actualmente de Parque Natural da Ria Formosa.

A palavra Cacela deriva do latim CASTELLUpelo ár. QasTallâ (DOELP, I, 303b), segundo Machado. A evolução -ST- para -ç- em moçárabe, que está atestada em apelativos e topónimos, deveuse a influência árabe, onde o fenómeno era comum ${ }^{1}$.

A informação histórica existente sobre Cacela tem sido escassa. No século XIX, o académico algarvio João Baptista da Silva Lopes escreveu a seu respeito: "conserva as ruínas dos antigos paços do concelho, as casas da residência do pároco, e sacristão com mais quatro ou seis moradas: para a banda do norte se tem encontrado alicerces e ruínas, que indicam ter sido ali a antiga vila" (Lopes, 1841, 323, 387).

Posteriormente, Sebastião Estácio da Veiga, pioneiro da arqueologia portuguesa fez o levantamento de vestígios arqueológicos na região algarvia, realizou escavações arqueológicas sistemáticas e recolheu materiais principalmente das épocas pré-histórica e romana e alguns de cronologia medieval. Elaborou a Carta Arqueológica do Algarve, utilizando a base cartográfica de Silva Lopes. Registou vários achados islâmicos nos concelhos de Loulé, Faro, na cidade de Tavira, quintas do Arroio e Trindade, Serro do Cavaco, sítio da Arrancada, Castro Marim, Alcoutim e Laranjeiras. Fez várias referências aos vestígios de época medieval que encontrou em Cacela:

i) "Além do elemento árabe, que mais aparentemente predomina com as ruinas do antigo castelo" (Veiga, 1887, vol.II, 397).

ii) “... já a quinta do Muro tinha fornecido um precioso monumento epigraphico moçárabe, de que a seu tempo e em lugar próprio darei notícia circunstanciada, e bem assim havia manifestado muitos vestígios de arrasados edifícios romanos" (Veiga, 1887, vol. II, 397).

iii) Apareceu (um machado de pedra) a pouca distância da "velha muralha mourisca" (Veiga, 1887, vol.II, 422).

1 Agradece-se a informação de Maria Alice Fernandes, Linguista da Universidade do Algarve que acrescentou ainda que "o - a- final de Cacela tanto pode provir da substituição do -o- final românico pelo sufixo topográfico árabe -a-, como ser etimológico". iv) Identificou na Manta $\operatorname{Rota}^{2}$ uma torre que interpretou como uma vigia de "Hisn-Castalla" e muitos fragmentos de louça vidrada e "daqueles preciosos jarrões ornamentados de relevo, que eram cingidos de inscrições cúficas" (Veiga, 1887, vol.II, 401).

v) Torre octogonal localizada no lugar da Torre dos Frades ${ }^{3}$. Estácio da Veiga terá encontrado possivelmente silos com "louças capituladamente árabes" (Veiga, 1887, vol. II, 423-425; Garcia, 2008, 154).

vi) "A outrora florescente vila de Cacela, hoje arrasada a ponto de não se conhecerem os antigos limites da sua grandeza, foi sucessora de mui anteriores populações, desde tempos remotíssimos, pois ali se acha largamente caracterizada a civilização neolítica, a romana e a árabe, como verifiquei, fazendo em vários lugares mui proveitosos reconhecimentos" (Veiga, 1887, vol. II, 580).

José Leite de Vasconcelos (1858-1941), fundador do actual Museu Nacional de Etnologia e Arqueologia, adquiriu duas candeias metálicas na freguesia de Cacela, que publicou na revista O Arqueólogo Português (Vasconcelos, 1902, 119).

Garcia Domingues (1910-1989), eminente arabista e professor na Universidade do Algarve, promoveu o estudo das fontes árabes e os primeiros ensaios históricos relacionados com as origens islâmicas de algumas localidades algarvias, como Cacela (Domingues, 1960, 1972).

António Borges Coelho, professor catedrático da Faculdade de Letras de Lisboa, organizou a compilação das fontes árabes sobre o território português e em 1973 publicou a obra Portugal na Espanha Árabe, integrando a biografia do poeta cacelense Ibn Darrague com a transcrição de alguns dos seus poemas (Coelho, 2008).

Assim, a referência documental mais antiga encontra-se na obra "Los caminos de al-Andalus (en el siglo XII)" de al-Idrisi, que descreve Cacela como um Castelo situado na rota marítima entre as cidades de Saltés e Santa Maria do Algarve.

O historiador Hugo Cavaco (1983) norteou o seu trabalho pela leitura e transcrição paleográficas das fontes existentes nos Arquivos Nacionais da Torre do Tombo, como a carta de foral de 1283, as cartas de doação do Castelo de Cacela à ordem de Santiago ou as Visitações da Ordem à região do Algarve oriental no século XVI.

2 Lugar situado junto do mar, cerca de dois quilómetros a este de Cacela

3 Propriedade situada a cerca de três quilómetros a nordeste de Cacela. 


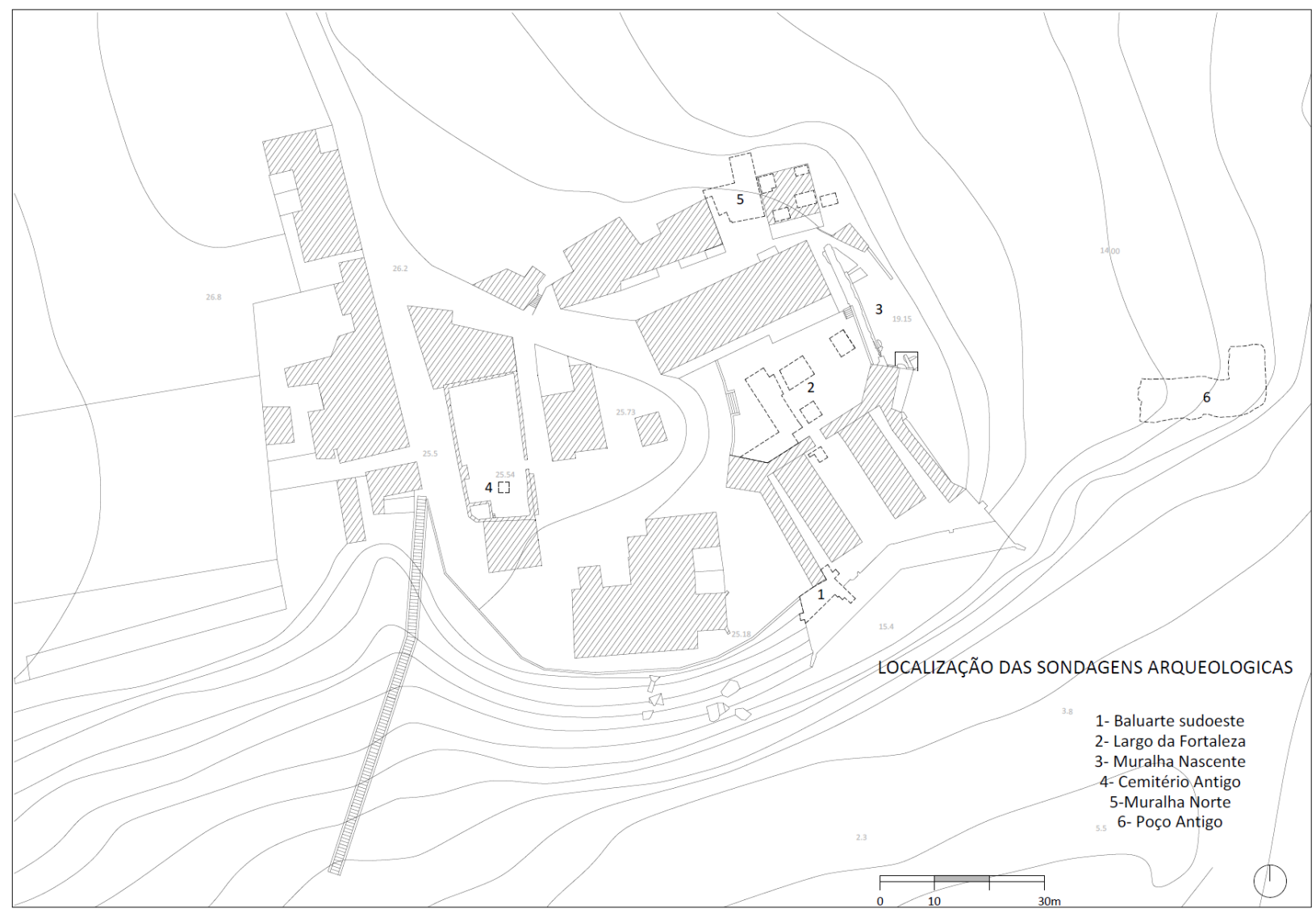

Figura 1: Localização das sondagens arqueológicas realizadas em Cacela-a-Velha.

Recentemente, Luis Oliveira, medievalista da Universidade do Algarve, publicou o documento mais antigo da Visitação à Comenda de Cacela, datado de 1478-1482 (Oliveira, 2008).

A epigrafia medieval árabe foi tratada inicialmente pelas investigadoras Ana Labarta e Carmen Barceló, apoiadas no primeiro estudo de A. Nykl de 1940. Fizeram o levantamento das inscrições epigráficas portuguesas, no qual incluiram a pia de abluções encontrada em Cacela (Labarta e Barceló, 1987).

As escavações arqueológicas com carácter científico em Cacela-a-Velha, iniciaram-se em 1998, prolongando-se de forma intermitente até 2007 (Figura 1). Contaram com a colaboração de várias instituições académicas e da administração local e regional.

A intervenção arqueológica decisiva foi a descoberta do Bairro Islâmico do Poço Antigo, escavado em 1998 e 2001 (Garcia, 2002; Garcia e Curate, 2010) ${ }^{4}$. Naquele ano foi realizada a obra de con-

4 Financiado pelo programa comunitário FEDER (art. solidação da parede de taipa localizada a nascente do povoado, que mereceu acompanhamento arqueológico. Em 2004 promoveu-se a realização de sondagens arqueológicas no largo da Fortaleza de Cacela (Garcia, Macedo e Lobo, 2006)5 , escavação arqueológica que foi ampliada em 2007.

Em 2006 a signatária apresentou a tese de mestrado na Universidade de Huelva, subordinada ao tema "Intervenção integrada no património cultural e sustentabilidade do mundo rural. Um modelo arqueológico para o Algarve”, no qual foi incluída a carta arqueológica, arquitectónica e do património etnográfico do território de Cacela (Garcia, 2008).

Presentemente, a signatária finaliza a tese de doutoramento intitulada "Cacela-a-Velha no contexto da actividade marítima e do povoamento rural do sudoeste peninsular nos séculos XII-XIV" sob a orientação dos Professores Juan Campos Carrasco e

$10^{\circ}$ ), projecto «Urbanismo islâmico do sul peninsular e norte de África», no âmbito da Acção Piloto Portugal-Espanha -Marrocos.

5 Projecto Castrum - Salvaguarda e Valorização dos Castelos, do programa MEDDOC III-B. 
Francisco Gómez Toscano da Universidad de Huelva. Este texto é uma síntese do estudo realizado.

\section{Objectivos Do ESTUdo}

Pretendemos com este estudo contribuir para o conhecimento histórico da região algarvia na Idade Média. O património arquitectónico e etnográfico, a tradição oral, as fontes históricas e as estruturas arqueológicas são elementos fundamentais da memória colectiva, como tal testemunhos desse percurso histórico. $\mathrm{Na}$ nossa pesquisa todos estes elementos encerram dados válidos. Com diferentes graus de valoração qualitativa, estes dados constituem "conquistas cumulativas" que concorrem para a corroboração da hipótese. A estratégia analítica consistiu em desenvolver uma rede descritiva de forma a organizar posteriormente o caso de estudo. Nesta tarefa, deparamo-nos inevitavelmente com questões e desafios, transformados em proposições teoréticas. Foram seleccionados os materiais e desenhadas as fichas descritivas Os dados serviram análises qualitativas e quantitativas, permitindo trabalhar em duas linhas que se entrecruzaram e fortaleceram a estratégia analítica (Yin, 2009, 130).

As análises quantitativas reportaram-se a alguns campos de análise neste estudo de caso em que as questões maiores eram de ordem qualitativa. A revisão da literatura nesta fase contribuiu para encontrar lacunas de informação histórica e tópicos de interesse na preparação do nosso caso de estudo. Os dados qualitativos permitiram explicar, explorar e avaliar o caso de estudo (Yin, 2009, 133).

O repertório analítico foi pacientemente construído, utilizando a lógica de correspondência de padrões. As hipóteses rivais fundadas em outro tipo de observações e influências funcionaram como variáveis independentes com o objectivo de testar o processo de análise do nosso caso de estudo, Cacela na época medieval (Yin, 2009, 136).

Assim, numa primeira fase, definiram-se os objectivos referenciais, pilares na construção de problemas e questões, fixação de metodologias e determinação de metas:

a) Inventário dos elementos patrimoniais de carácter arquitectónico e arqueológico;

b) Relatórios arqueológicos e laboratoriais;

c) Cartografia histórica;

d) Compilação das fontes históricas;
Transcorrida esta primeira etapa e perante os resultados inicialmente obtidos, formularam-se os objectivos da presente investigação:

1) Limites e organização da Alcáçova islâmica;

2) Arquitectura doméstica e vida quotidiana da população na fase final do período almóada, segunda metade do século XII-XIII;

3) Conquista cristã e povoamento do território na segunda metade do século XIII e XIV;

4) Evolução da fortificação nos séculos XIII-XVI;

Assim, partimos do princípio que a análise, selecção e cruzamento dos dados concorrem para o conhecimento do período de transição que ocorreu entre o povoamento islâmico, a fase de guerra e ocupação e o povoamento da região do Baixo Guadiana. Como vimos, este período histórico é bem conhecido do ponto de vista dos movimentos militares e políticos. Contudo, desconhecemos modos de vida ${ }^{6}$, migrações, construção da paisagem e arquitectura. A nossa pesquisa procurou abranger as questões-chave e o maior conjunto possível de evidências. Propomos analisar as fontes medievais portuguesas e árabes do ponto de vista da região ocidental do Gharb. Partimos do pressuposto que as características naturais do Baixo Guadiana, zona de raia, de povoamento instável, por vezes de indefinição, mantiveram alguma ligação ou coesão entre os habitantes e as actividades desenvolvidas. Cremos que o nosso trabalho pode contribuir para caracterizar as comunidades islâmicas da primeira metade do século XIII, o seu destino após a conquista da zona ocidental do Guadiana, a articulação com a instalação de novos poderes na região, a chegada de novos moradores, as práticas de exploração dos recursos naturais e a evolução arquitectónica dos lugares.

\section{MÉTodos De InVestigaÇÃo}

Neste estudo foram aplicadas metodologias de investigação histórica e arqueológica, cruzando a informação das fontes documentais com a interpretação das unidades estratigráficas, estruturas e análise dos materiais arqueológicos.

Fez-se a actualização bibliográfica das fontes históricas publicadas, da arqueologia almóada no Gharb-al-Andalus, da ocupação humana da orla costeira no período medieval e a contextualização

6 Neste campo, têm contribuído os estudos zooarqueológicos realizados por alunos de mestrado da Universidade do Algarve, sob a coordenação de Maria João Valente, que em conjunto, darão um forte impulso na caracterização da dieta alimentar e paisagem medieval algarvias. 




Figura 2: Povoamento da orla costeira do sudoeste ibérico. Séculos XII-XIII (a partir dos inventários arqueológicos).

histórica dos eventos de carácter político-militar e povoamento do Baixo Guadiana entre os séculos XIII e XVI.

Os dados recolhidos foram integrados num sistema relacional de bases de dados, realizado através do programa "Filemaker". Este software permitiu manter os registos no seu contexto e na sua complexidade, obter o armazenamento consistente de um banco de dados de elevada dimensão, criar uma acessibilidade eficaz aos diferentes tipos de informação pretendida e relacionar dados conexos. As bases de dados criadas tinham um grupo de palavras-chave comum, que permitiam agrupar e reduzir informação de uma forma sólida em função de atributos cronológicos, geográficos, históricos e temáticos. Foram criadas as seguintes bases de dados:

a) Ficha bibliográfica: composição dos campos tradicionais de referência bibliográfica, depósito da obra e cota, sumário (notas e comentários), arquivo de imagens e acesso directo a publicações online. Foram introduzidos 1240 registos.

b) Portos e povoações costeiras: campos de identificação do lugar (nome, variantes do nome, localização, cronologia da fundação, cronologia de ocupação); referências das fontes históricas; campos de dados arqueológicos medievais islâmicos e medievais cristãos (séculos XIII/XIV) sub-divididos em registos de arquitectura, materiais e zooarqueologia (com indicação de referência bibliográfica); campo de registo de intervenientes (com conexão à base Intervenientes). Foram introduzidos 46 registos (parcial).

c) Intervenientes: identificação da pessoa (nome, variantes do nome, naturalidade, residência, anos de nascimento e morte, idade referida em registo documental), profissão, povoações visitadas e actividades realizadas (com conexão à base Eventos/Cronologia), relações inter-pessoais, referências bibliográficas). O teste de operacionalidade foi positivo.

$\mathrm{Na}$ fase analítica da componente arqueológica de Cacela, este sistema permitiu estabelecer paralelos com sítios arqueológicos da região algarvia e restantes povoações e portos costeiros do golfo ibero-marroquino (sítios com funções portuárias, vigilância da entrada em rios e acesso a cidades ou com actividades piscatórias) através da análise de tipologias arquitectónicas e arqueológicas. $\mathrm{O}$ objectivo foi compreender o carácter do povoamento e das actividades de Cacela, bem como possíveis contactos e relações comerciais, mas o sistema revelou possuir características mais abrangentes para o território em análise.

A pesquisa foi alicerçada numa síntese histórico -arqueológica do ponto de vista das regiões algarvia e andaluza, cruzando os dados sobre os acontecimentos militares, políticos e actos administrativos ocorridos entre os séculos IX e XIII com os dados arqueológicos publicados. Obteve-se um interes- 
sante mapeamento do povoamento da orla costeira destas regiões, trabalho em fase experimental, mas que se revelou profícuo, podendo ser desenvolvido num tempo futuro no âmbito da cooperação académica abrangendo as regiões em estudo (Figura 2).

A prospecção arqueológica e inventário do património cultural imóvel da actual freguesia de Vila Nova de Cacela foram realizados no âmbito do trabalho de mestrado 7 e encontra-se publicado (Garcia, 2008). Sempre que possível, procedeu-se a recolha de elementos de diagnóstico, como análises petrográficas e de argamassas, levantamentos fotográficos, análises de radiocarbono, sondagens geotécnicas, prospecção de campo e recolha do testemunho oral junto dos anciãos moradores na zona.

No que refere o método arqueológico, no terreno foi feita a implantação de uma quadriculagem (de 2 metros) integrada no sistema geodésico nacional. Foi aplicado o sistema de escavação arqueológica e princípios de estratigrafia arqueológica de Harris (1991). Assim, as escavações arqueológicas realizaram-se levantando sucessivamente as camadas naturais, designadas por unidades estratigráficas, as "ue", numeradas por ordem de surgimento.

As escavações arqueológicas abrangeram a vertente nascente de Cacela-a-Velha (Poço Antigo) e no interior da povoação, no Cemitério Antigo, Largo da Fortaleza e interior da Fortaleza setecentista.

A utilização de bases de dados em ficheiros Filemaker e Excel permitiu aplicar métodos descritivos, analíticos e comparativos das características, textura, cotas, áreas de ocorrência e inter-relações das camadas. Os materiais arqueológicos foram analisados com o objectivo de identificar funcionalidades associadas aos espaços domésticos, a caracterização da dieta alimentar dos habitantes, o padrão do povoamento local e a sua relação com o espaço envolvente. Por outro lado, a análise comparativa das sequências estratigráficas conjugada com o estudo dos materiais recuperados e a leitura dos restos construtivos permitiu identificar horizontes históricos.

A realização da tarefa de classificação e análise das cerâmicas de Cacela-a-Velha seguiu uma metodologia, que passou pela selecção das amostras, adopção de um modelo tipológico, elaboração de base de dados, inventário, descrição e classificação

7 Estudo realizado na Universidade de Huelva sob a orientação do Professor Francisco Goméz Toscano, no âmbito do Programa de Doctorado em Património Histórico e Natural. das peças e, finalmente a análise e interpretação histórica do conjunto.

\section{A INTERVENÇÃo ARQUEOLÓGICA}

\section{A) Alcáçova}

$\mathrm{Na}$ plataforma superior, onde se localiza a fortaleza setecentista, igreja matriz e algum casario foram realizadas sondagens e escavações arqueológicas no Largo da Fortaleza, que se prolongaram no interior até ao baluarte sudoeste, no Cemitério Antigo e no sector nascente junto do paredão de taipa de época moderna. Escavações arqueológias de acompanhamento de obra foram realizadas junto da Muralha Norte ${ }^{8}$.

Estes trabalhos arqueológicos permitiram identificar os seguintes níveis de ocupação:

$\left.1^{\circ}\right)$ Construções de época indeterminada, hipoteticamente da Antiguidade Tardia.

$\left.2^{\mathrm{o}}\right)$ Construções islâmicas indeterminadas, hipoteticamente do final séc.IX-X.

$3^{\text {o) }}$ Ocupação e abandono na época almóada. Segunda metade do século XII- primeira metade do século XIII.

$\left.4^{\circ}\right)$ Ocupação medieval cristã. Obras de reforço da fortificação. Construção da igreja matriz de uma nave. Segunda metade do século XIII -XIV.

$\left.5^{\circ}\right)$ Obras de reconstrução da Igreja e Fortaleza. Primeira metade do século XVI.

$\left.6^{\circ}\right)$ Construção de algum casario no século XVI -XVII.

$\left.7^{\circ}\right)$ Nível de destruição causado pelo terramoto do século XVIII.

$\left.8^{\mathrm{o}}\right)$ Reconstrução da fortaleza na segunda metade do século XVIII.

$\left.9^{\circ}\right)$ Nível de lixeiras e abandono dos séculos XIX-XX.

$\left.10^{\circ}\right)$ Repavimentação dos espaços públicos em 1980.

A implantação das estruturas antigas e islâmicas ocorreu em substrato rochoso constituído por solos silto-argilosos coesivos muito duros de côr amarelo-esverdeada, por vezes com algumas raízes e escassos blocos pétreos, carvões, caliço e fragmentos cerâmicos. Estas camadas assentavam na rochamãe do período Miocénico. Verificou-se que a fase de construção almóada alterou substancialmente a

8 Estas intervenções foram realizadas pela empresa $\mathrm{Pa}-$ limpsesto, a quem agradecemos as informações prestadas. 
organização espacial anterior. Este período de ocupação deixou amplos resíduos da vida quotidiana, maioritariamente cerâmicos, em todos os níveis escavados. Por isso, não foi possível registar níveis estratigráficos de períodos anteriores, apenas coincidências entre estruturas e materiais romanos.

\section{B) Bairro do Poço Antigo}

$\mathrm{Na}$ vertente nascente do castelo, fora do perímetro amuralhado, o sítio arqueológico do Poço Antigo situa-se em terreno agrícola, próximo da ria e na margem direita da ribeira das Hortas. O terreno tem um declive acentuado, estendendo-se entre a cota dos 20 metros, junto à muralha a poente, e a cota dos 2 metros na margem da ribeira, a nascente. A escavação arqueológica decorreu na zona jusante do terreno.

Este lugar assenta numa frente litoral terrestre composta por conglomerados e siltes miocénicos com predominância de siltes glauconíticos amarelo-torrados (Manupella et al, 1987: 29).

As escavações arqueológicas permitiram identificar as seguintes fases de ocupação:

Fase I: A construção e ocupação do Bairro Islâmico, provavelmente na segunda metade do séc. XII.

Fase II: O abandono e derrocada do Bairro no final do período almóada. Primeira metade do século XIII;

Fase III: A ocupação do sítio arqueológico por areias. Meados do século XIII;

Fase IV: Nível de ocupação medieval cristã. Ermida de Nossa Senhora dos Mártires e necrópole. Segunda metade do século XIII e século XIV;

Fase V: Revolvimentos da época moderna;

Fase VI: Terras agrícolas de ocupação recente;

As escavações arqueológicas do sítio do Poço Antigo revelaram um conjunto habitacional do período almóada, Fase I.

As casas estavam abrigadas dos ventos dominantes de oeste pela presença do castelo, confinavam a sul e a nascente com ambiente marinho e a sua vertente nordeste pode ter sido protegida por fosso. As casas postas a descoberto são de pequena ou média dimensão e correspondem a diferentes tipologias de casas urbanas islâmicas. Foram estruturadas em forma de bairro, que terá sido edificado mediante um programa construtivo de época almóada (Torres, 1992; Navarro Palazón, 1990), como tal, obedecendo a algumas regras de organização do espaço, circulação pública e drenagem de águas pluviais.
As casas foram construídas num mesmo momento. Não se encontram vestígios de uma longa utilização, como por exemplo, as camadas sucessivas de rebocos que são visíveis na casa $5 \mathrm{~N}$ de Saltés (Bazzana e Bedia, 2005, fig. 168) e nos compartimentos descobertos na plataforma superior do castelo de Cacela. A última fase de ocupação das casas evidencia uma reduzida representação estratigráfica. Nos anos finais de vida do bairro, verifica-se a degradação das estruturas e a fraca manutenção e reparação das mesmas. O abandono das casas terá acontecido de forma gradual.

$\mathrm{Na}$ Fase II, verificou-se o abandono e a derrocada parcial das construções, provavelmente no período almóada final, primeira metade do século XIII. Foi analisada a estratigrafia que integrava os últimos testemunhos físicos (cerâmicas, metais) dos habitantes, sobrepostos e envolvidos pelos derrubes de coberturas e paredes.

$\mathrm{Na}$ Fase III o sítio foi invadido por areias miocénicas que preencheram as construções ainda alçadas e cobriram as ruínas existentes, atingindo por vezes $100 \mathrm{~cm}$ de espessura. Nestas areias foram recolhidas em quantidade, cerâmicas predominantemente almóadas e restos alimentares.

$\mathrm{Na}$ Fase IV evidenciou-se a organização do lugar do Poço Antigo pelos novos senhorios, a Ordem de Santiago. O lugar foi sacralizado através de uma queimada conduzida, o que provocou o derrube das construções sobreviventes, delimitando, deste modo o novo espaço funerário cristão. Foram descobertas 56 sepulturas e 14 reduções, num total de 74 indivíduos, desconhecendo-se a dimensão real desta necrópole. As fossas das sepulturas foram abertas nas ruínas das habitações islâmicas, cortando restos de telhados, derrubes, camadas e atravessando muros. Algumas sepulturas aproveitam as pedras dos muros na delimitação das suas cabeceiras. Esta aposição poderá encontrar-se relacionada com uma sublimação ou monumentalização da vitória dos cristãos sobre os muçulmanos. Encontramos situações semelhantes em Mértola, Silves e Palmela (Candón, 1999; Gomes, 2006, 221; Fernandes, 2004, 85).

$\mathrm{Na}$ necrópole medieval de Cacela todos os indivíduos exumados se encontravam orientados para nascente, depostos em posição de decúbito dorsal com os braços normalmente cruzados sobre o peito ou abdómen, observando-se variações mínimas entre $240^{\circ}$ e $270^{\circ}$. Não foram detectados outros padrões de organização do espaço sepulcral. 
A comprovar-se a eventual existência da igreja matriz primitiva, verifica-se que a disposição das sepulturas no terreno obedeceu provavelmente à orientação poente-nascente do templo. Verificouse uma homogeneidade do tipo de enterramento. As sepulturas caracterizavam-se por fossas simples abertas em solo arenoso. Verificou-se ainda a repetida reutilização das sepulturas, pela congregação de reduções, normalmente junto dos membros inferiores ou ossários, zonas de depósito de ossos, fruto da limpeza de uma determinada zona sepulcral, já sem qualquer preocupação em ritualizar aqueles conjuntos.

As Fases V e VI não foram alvo do presente estudo.

\section{CONCLUSÕES}

Desconhece-se a origem da alcáçova de Cacela, mas afigura-se verosímil recuar aos períodos emiral ou califal. $\mathrm{O}$ achado de peças de boa execução e qualidade artística datáveis do século $\mathrm{X}$, são reveladoras, em nossa opinião, da existência de uma comunidade com vivência inter-regional.

A topografia da pequena elevação onde assentaria a alcáçova revela que a frente marítima estaria naturalmente protegida pelo acentuado declive da arriba, que dificultava o acesso a intrusos. Os sectores norte e oeste eram de fácil acesso, tendo sido implantadas fortes muralhas.

No interior da alcáçova, três patamares articulados entre si, proporcionaram leituras distintas. $\mathrm{O}$ patamar superior, ocupado presentemente pelo Cemitério Antigo, Casa Paroquial, cisterna e Igreja, poderia corresponder ao alcácer, espaço militar e mesquita da povoação. Aqui poderiam ser desempenhadas actividades públicas ou associadas à administração do castelo e seu alfoz. No patamar intermédio localizavam-se a residência senhorial e dos funcionários e os silos da comunidade. O patamar inferior seria ocupado por bairro possivelmente militar situado junto da muralha norte e por arriba a este, por onde seriam escoadas águas residuais e despejados lixos domésticos.

Verificou-se a existência de estruturas possivelmente habitacionais anteriores à ocupação islâmica que apontam para uma ocupação de Cacela que pode remontar aos séculos VI/VII ${ }^{9}$.

9 Cabe agradecer a Maria Maia e Manuel Maia, colegas do Campo Arqueológico de Tavira a visita que realizaram aos trabalhos arqueológicos em 2007, a análise dos elementos e a proposta de datação.
O reforço de taipa da muralha norte e os muros de taipa presentes naquele sector poderão pertencer ao segundo momento de intervenção arquitectónica em Cacela, que poderá ter ocorrido no período das primeiras taifas ou mesmo em época almorávida.

Estes muros de taipa foram provavelmente substituídos por uma intervenção com carácter urbano no periodo almóada. Todos os sectores arqueológicos escavados continham níveis de abandono da primeira metade do século XIII.

Esta descontinuidade no casario em relação com épocas anteriores ao período almóada foi observada em Sevilha. Nesta cidade, importantes obras públicas foram executadas a partir de 1171 (Valor, 2008: 170).

Fora do perímetro amuralhado da alcáçova, em zona ribeirinha de ria e da ribeira das Hortas, situava-se o bairro do Poço Antigo.

Encontramos algumas semelhanças da população deste bairro com as populações do Castelo de Salir (Catarino, 1997-98) e Villa Vieja (Pozo, Robles e Navarro, 2002: 161 e ss.), localizadas no interior das regiões de Ossónoba e Tudmir, comunidades rurais, com áreas de construção das habitações modestas, que utilizam o mesmo tipo de matérias - primas e técnicas construtivas e têm ausência de latrinas ${ }^{10}$, apesar de Villa Vieja incluir um sistema viário ortogonal.

Os testemunhos materiais do bairro islâmico do Poço Antigo denotam a capacidade de comunicação e intercâmbio entre os habitantes do al-Andalus. Assim, os pequenos brincos de campânula, as torres de roca ou as plaquetas assemelham-se em detalhe, aos objectos encontrados no castillo de la Torre Grossa, na região valenciana (Azuar, 1989, $183,204,212)$. E os pequenos fragmentos com decoração esgrafitada poderão ser provenientes da região murciana.

Certos objectos possuem uma longa tradição de continuidade no quotidiano das malgas comunidades rurais, como os alguidares, cântaras, tampas e testos, pelo que têm sempre um "ar de família”, independentemente da sua proveniência. De forma que a maior parte dos utensílios cerâmicos encontrados em Cacela filia-se no conjunto de louça doméstica do ocidente do al-Andalus.

Encontra-se bem representado o universo de recipientes cerâmicos necessários ao funcionamen-

10 Mais de metade das casas de Villa Vieja carece de latrina. 
to de uma estrutura doméstica na época almóada. Regista-se a ideia de que a região tinha capacidade para fabricar a maior parte da louça de serviço doméstico e tinha acesso a alguma louça de mesa ou ás grandes talhas estampilhadas de provável importação. $\mathrm{O}$ conjunto cerâmico do Poço Antigo coincide pois com os acervos de Silves, Mértola e Niebla/Saltés (Campos, Gómez y Pérez, 2006), em que Sevilha, no papel de capital do império, era o centro difusor de um território coeso com estreitos contactos comerciais (Fernández, 1987, 465, 471).

No conjunto, Cacela almóada possuía a louça que caracterizava aquele período histórico, revelando um ambiente mundano para a época em estudo. As pastas claras decoradas com estampilhados verdes requintados, como as talhas, candeias de pé, tigelas e tigelinhas, tampas e vasos foram importadas. Assim como as jarrinhas de pastas claras e paredes finas pintadas de côr branca. As tigelas e tigelinhas existiam em variados tamanhos e formas, decoradas com vidrados melados e pinturas em manganés. A decoração em corda seca é rara nesta colecção. Uma jarrinha miniatura decorada com pingos de manganés trouxe à memória o uso de essências aromáticas naturais. A presença de objectos semelhantes a exemplares encontrados, por exemplo, na região valenciana, confirma a sólida rede de comunicação existente no império almóada, encontrando-se ainda em Cacela representantes do apogeu artístico da época.

A variedade de formas dos utensílios afasta $\mathrm{Ca}$ cela do estatuto de povoação rural, como o castelo de Salir ou La Almagra de Huelva.

Cacela é uma povoação portuária, portanto, integrada no mundo costeiro da bacia de Cádis e no momento histórico de coesão do poder almóada no ocidente do al-Andalus.

Após a conquista do castelo pela milícia da Ordem de Santiago em 1240, as suas muralhas terão sido preservadas e mantidas. Neste sentido, foi edificada uma barbacã, muro de primeira defesa que rodeava as muralhas do castelo.

No recinto, verificou-se o abandono e aterro das construções islâmicas. Os santiaguistas iniciaram então a construção de nova fortificação no extremo sudeste da alcáçova. As muralhas da frente marítima e flanco oriental foram reaproveitadas e ter-se-á construído os lados norte e ocidental por forma a criar um quadrilátero com torres nos cantos.

Em Mértola, a construção da torre de menagem estava concluída em 1292. Nesta altura, Mértola foi a primeira sede nacional da ordem de Santiago, sendo o seu mestre, João Fernandes (Torres et al, 1991, 18). A questão que se coloca é de que forma seria feita a gestão dos efectivos santiaguistas nas obras em curso no sudeste algarvio e Alentejo oriental, naquela época. Em Mértola, provavelmente foram utilizados como mão-de-obra combatentes muçulmanos, uma vez que a cidade foi tomada pela força. Mas como se terá conciliado esta obra com outras obras de vulto, como a construção da nova fortaleza em Cacela, é assunto que desconhecemos.

Em Cacela, verifica-se que na segunda metade do século XIII terá existido o programa de construção da nova fortificação com alojamento dos militares, da igreja e casas da paróquia. Enquanto decorriam as obras, foi criado um espaço para cumprimento dos rituais religiosos, no exterior do castelo, onde antes existia o bairro islâmico portuário. Ali foi construída a primeira igreja da comenda de Cacela, da invocação de Nossa Senhora dos Mártires com cemitério adossado (Cavaco, 1987, 24, 275).

Este programa de obras estaria naturalmente associado ao processo de autonomização do ramo português da ordem de Santiago (Boiça e Barros, 2002, 579).

Os castelos de Cacela e Aiamonte foram doados, ainda naquele ano de 1240, ao comendador-mor português da Ordem de Santiago, Paio Peres Correia, pelo bom serviço prestado ao monarca (Oliveira, 2009). O termo do castelo de Cacela estendia-se até ao rio Guadiana. O termo de Aiamonte limitava a nascente com o rio Odiel e sustentava militarmente a zona de fronteira com o reino de Niebla (Livro dos Copos, 2006, 327, 701; Cavaco, 1983, 61).

O início da utilização do espaço sepulcral parece coincidir com o momento de conquista do castelo de Cacela, segundo as fontes históricas e os dados arqueológicos. Por volta de 1260 , terá sofrido um incêndio e consequente destruição, concordante com o ambiente instável existente na região. Assim, as estruturas funerárias registadas são assaz despretensiosas e espelham, porventura, o status económico e aspectos do quotidiano da população medieval cristã de Cacela, decorrente do ambiente instável vivido na região por força dos conflitos existentes com o al-Andalus e, posteriormente com Castela.

Os dados arqueológicos reforçam a ideia de que o povoamento cristão da região iniciou-se pouco depois da conquista. Assim, o ano de 1240 marcou a conquista, possivelmente a reorganização administrativa e o estabelecimento de novos povoadores. 
O castelo de Cacela e a Ordem de Santiago terão sido no terceiro quartel do século XIII os elementos agregadores e polo religioso dos moradores do levante algarvio e do termo de Aiamonte.

A igreja de Nossa Senhora dos Mártires pode, assim, ter sido a primeira paróquia rural da região do Baixo Guadiana. As datações de radiocarbono abonam a favor desta hipótese. As características das sepulturas, maioritariamente compostas por covas simples abertas na areia, reflectem igualmente a sua antiguidade. São parte da população civil do sotavento algarvio, cuja caracterização demográfica, paleopatológica e hábitos alimentares ficaria mais completa, através da escavação arqueológica da totalidade daquela área.

\section{Bibliografia}

Al-Idrisi (1989), Los caminos de al-Andalus en el siglo XII según Uns al-Muhay wa-Rawd al-Furay (trad. J. A. Mizal), Consejo Superior de Investigaciones Científicas, Madrid.

Azuar Ruiz, R. (1989), Denia Islámica. Arqueologia y poblamiento, Instituto de Cultura Juan Gil-Albert, Alicante.

Candón, A. (1999), "La colección antropológica del Campo Arqueológico de Mértola (s. II-XVI). Reconstruir la sociedad y los modos de vida a partir del registro funerario", Arqueologia Medieval, 6, 277-292.

Cavaco, H. (1983), A antiga vila de Cacela e o seu alfoz, Câmara Municipal de Vila Real de Santo António, Vila Real de Santo António.

Cavaco, H. (1987), Visitações" da ordem de Santiago no Sotavento Algarvio - Subsídios para o estudo da História da arte no Algarve, Câmara Municipal de Vila Real de Santo António, Vila Real de Santo António.

Coelho, A. B. (2008), Portugal na Espanha Árabe ( $3^{a}$ edição), Editoral Caminho Lisboa.

Domingues, J. G. (1960), O Garb extremo do Andaluz e "Bortuqal" nos historiadores e geógrafos árabes, Separata do Boletim da Sociedade de Geografia de Lisboa, JulhoDezembro, Lisboa, 327-362.

Domingues, J. G. (1972), Ossonoba na época árabe, Separata dos Anais do Município de Faro, Câmara Municipal de Faro, Faro.

Fernandes, I. C. (2004), O Castelo de Palmela: do islâmico ao cristão, Edições Colibri, Lisboa.

Fernández Gabaldón, S. (1987), "El yacimiento de la Encarnación (Jerez de la Frontera): bases para la sistematización de la cerámica almohade en el S.O. peninsular”, Al-Qant,ara, VIII, 449-474.

Fonseca, A. -Dir- (2006), Livro dos Copos (2006), Militarium Ordinum Analecta, 7, Porto.

García, C. (2002), "Urbanismo islâmico em Cacela, uma intervenção inovadora na região do Algarve", Urbanismo islâmico en el sur peninsular y norte de África, Murcia, 21-38. Murcia.

García, C. (2008), Cacela, terra de Levante. Memórias da paisagem algarvia, Câmara Municipal de Vila Real de Santo António e Campo Arqueológico de Mértola, Vila Real de Santo António.

Garcia, C. e Curate, F. (2010), "Resultados preliminares do estudo da necrópole medieval de Cacela Velha”, IV Congresso de Arqueologia Peninsular, Promontoria Monográfica, 13, 223-232.

García, C., Macedo, S. e Lobo, F. S. (2006), "Resultados preliminares da intervenção arqueológica realizada na Fortaleza de Cacela”, Actas do $3^{\circ}$ Encontro de Arqueologia do Algarve, Xelb, 6, 179-188.

Gomes, R. V. (2006), Silves (Xelb), uma cidade do Gharb Al-Andalus: o núcleo urbano, Trabalhos de Arqueologia, 44. Lisboa.

Harris, E. C. (1991), Principios de estratigafía arqueológica, Editorial Crítica, Barcelona,

Labarta, A. e Barceló, C. (1987), "Inscripciones árabes portuguesas: situación actual", $A l$ Qantara, VIII, 395-420.

Lopes, J. B. da S. (1841), Corografia ou memória económica, estatística e topográfica do reino do Algarve, Faro, Reedição.

Machado, J.-Ed.- (2003), Dicionário onomástico etimológico da língua portuguesa, Livros Horizonte, Lisboa.

Navarro Palazón, J. (1990), "La casa andalusí en Siyāsa: ensayo para una clasificación tipologica", La casa hispano-musulmana. Aportaciones de la Arqueología (Bermúdez López e Bazzana, Coords.), Granada, 177-198.

Oliveira, L. F. (2008), “A comenda de Cacela e a visitação de 1478-1482”, Sic memorat. Estudos em homenagem a Teresa Júdice Gamito, Faro, 139-151.

Oliveira, L. F. (2009), “A Ordem de Santiago em Portugal: a conquista das terras do Sul (séculos XII-XIII)", V Congreso Nacional sobre la Cultura en Andalucia. La Orden Militar de 
Santiago Fortificaciones y Encomiendas, no prelo.

Pozo Martínez, I., Robles Fernández, A. e Navarro Santa-Cruz, E. (2002), "El despoblado andalusí de Villa Vieja (Hisn Qalashbarra). La transformación de una alquería en un hisn de la cora de Tudmir" Urbanismo islámico en el sur peninsular y norte de África, Murcia, 146-195.

Torres, C. (1992), "O espaço familiar e formas de habitar no Garb al Andaluz" Actas das $I^{a} s$ Jornadas de cerâmica medieval e pósmedieval. Métodos e resultados para o seu estudo, Tondela, 33-40.

Torres, C., Palma, M. P., Rego, M. e Macías, S. (1991), "Cerâmica islâmica de Mértola - propostas de cronologia e funcionalidade", A cerâmica medieval no Mediterrâneo Ocidental (L.A. Silva e R. Mateus, Coords.), Lisboa, 497-536.

Valor Piechotta, M. (2008), Sevilla almohade, Editorial Sarriá.

Vasconcelos, J.L. (1902), "Candeias arabes do Algarve”, O Archeologo Português, VII/4-5, 119-123.

Veiga, S.F.M. Estácio (1886-1891), Antiguidades monumentaes do Algarve. Tempos prehistoricos, Lisboa.

Yin, R. K. (2009), Case study research. Design and methods ( $4^{a}$ edição). Applied social research methods series, Sage Publications, London-New Delhi. 
